\title{
A Multi-redox Responsive Cyanometalate-based Metallogel
}

\author{
Kiyotaka Mitsumoto, ${ }^{[a]}$ Jamie M. Cameron, ${ }^{[a]}$ Rong-Jia Wei, ${ }^{[a]}$ Hiroyuki Nishikawa, ${ }^{[b]}$ Takuya Shiga, ${ }^{[a]}$ \\ Masayuki Nihei, ${ }^{[a]}$ Graham N. Newton, ${ }^{*[a] c]}$ Hiroki Oshio*[a]
}

\begin{abstract}
A tetrathiafulvalene (TTF) based tridentate ligand $(\alpha-(4)$ methyl-4,5-di- $n$-dodecylthylthiotetrathiafulvalene-5'-ylthio)- $\alpha^{\prime}$-[tris2,2,2-(1-pyrazolyl)ethoxy]-p-xylene) (L) with long-chain alkyl moieties was prepared in order to obtain a new multi-redox active gelator based on a mixed-metal octanuclear complex $\left[\mathrm{Fe}^{\mathrm{III}}{ }_{4} \mathrm{Ni}_{4}{ }_{4}(\mathrm{CN})_{12}(\mathrm{tp})_{4}(\mathrm{~L})_{4}\right]\left(\mathrm{BF}_{4}\right)_{4}(\mathbf{1})$. The magnetism, electrochemistry and gelation behaviour of $\mathbf{1}$ were studied and 1,2-dichlorobenzene solutions of $\mathbf{1}$ are shown to display thermoreversible gelation behaviour at room temperature. Furthermore, the gel phase of $\mathbf{1}$ is shown to undergo room-temperature gel-to-sol transformations induced by both the oxidation and reduction of the gelator complex by $\mathrm{F}_{4} \mathrm{TCNQ}$ or $\left[\mathrm{Fe}^{\prime \prime}\left(\mathrm{Cp}^{*}\right)_{2}\right]$, respectively.
\end{abstract}

Low-molecular-weight gelators (LMWGs) are known to show reversible sol-gel phase transitions upon thermal stimuli. ${ }^{[1]}$ This bi-stability arises as a result of control over intermolecular organization originating from dipole-dipole, van der Waals, and hydrogen bonding interactions. When the temperature is decreased below the sol-gel transition temperature $\left(T_{\mathrm{s}-\mathrm{g}}\right)$, the low-weight molecules aggregate to form nanoscopic morphologies such as one-dimensional fibers, two-dimensional sheets or three-dimensional aggregates, which are often crystalline and generally coincide with the trapping of solvent molecules. ${ }^{[1]}$ In recent years, the obvious potential for the design of new gelators with controllable responses to a variety of external stimuli (such as redox-, photo- and chemo-responsive systems) has led to a considerable increase in interest in the field, particularly with respect to the design of new, 'smart' soft materials with externally triggered physical and/or chemical responses. ${ }^{[2]}$

Various LMWGs have been reported to date, but systems exploiting the rich array of properties available to transition metal complexes (i.e. metallogels) are still relatively limited, even though such complexes may confer a variety of unique chemical and physical properties to the functionalized organogels. ${ }^{[3]}$ In particular, LMWGs incorporating multi-nuclear transition metal complexes have not been widely reported, with the notable exception of a select few di- or tri-nuclear systems. ${ }^{[3 \mathrm{~d}, \mathrm{e}]}$ The design of discrete, poly-nuclear metal complex incorporating

\footnotetext{
[a] Dr. K Mitsumoto, Dr. J. M. Cameron, Dr. R.-J. Wei, Dr. T. Shiga, Prof. Dr. M. Nihei and Prof. Dr. H. Oshio Graduate School of Pure and Applied Sciences University of Tsukuba, Tennodai 1-1-1, Tsukuba, 305-8571 (Japan) E-mail: oshio@chem.tsukuba.ac.jp

[b] Prof. Dr. H. Nishikawa Department of Chemistry, Faculty of Science, Ibaraki University 2-1-1 Bunkyo, Mito, Ibaraki, 310-8371 (Japan)

[c] Dr. G. N. Newton School of Chemistry, University of Nottingham University Park Nottingham, NG7 2RD (UK)
}

gelators possessing inherent multi-redox behaviour may therefore contribute to the development of unique functional gels, such as those with multi-step isothermal sol-gel-transformations induced by the changes in the electronic state of the multinuclear core. We have previously reported that cyanide-bridged octanuclear complexes with TTF moieties exhibited multi-step redox processes involving eight- or twelve-electron transfers. ${ }^{[4]}$ Thus, they are expected to behave as discrete, electronically active gelating units, paving the way towards new multi-redox LMWGs. ${ }^{[5]}$

Here, the synthesis, gelation properties and electrochemical studies of both the tridentate thioalkyl TTF-based ligands $\left(\left(\alpha-\left(4^{\prime}-\right.\right.\right.$ methyl-4,5-di-n-dodecylthylthiotetrathiafulvalene-5'-ylthio)- $\alpha$ [tris-2,2,2-(1-pyrazolyl)ethoxy]-p-xylene)) (L) (Fig. 1a), which in turn support a new octanuclear gelator complex $\left[\mathrm{Fe}^{\prime \prime \prime \prime}{ }_{4} \mathrm{Ni}_{4}{ }_{4}(\mathrm{CN})_{12}(\mathrm{tp})_{4}(\mathrm{~L})_{4}\right]\left(\mathrm{BF}_{4}\right)_{4}, \quad$ (1) $\quad$ (where tp = trispyrazoleborate) (Fig. 1b) are presented. This complex formed a red semi-transparent gel from 1,2-dichlorobenzene solutions and showed thermally reversible sol-gel transitions. Furthermore, gel-to-sol transformations could be induced by redox interactions with both $\mathrm{F}_{4} \mathrm{TCNQ}(2,3,5,6$-tetrafluoro-7,7,8,8tetracyanoquiodimethane) and $\left[\mathrm{Fe}^{\prime \prime}\left(\mathrm{Cp}^{*}\right)_{2}\right]$ (decamethylferrocene), exploiting both the electron donating and accepting character of $\mathbf{1}$.

The TTF-based ligand (L) was first synthesized in $86 \%$ yield according to Scheme S1 (see SI). Compound 1 could then be isolated by employing a simple self-assembly approach, reacting equal equivalents of $\mathrm{Ni}\left(\mathrm{BF}_{4}\right)_{2}, \mathbf{L}$ and a $\left[\mathrm{Fe}^{\text {III }}(\mathrm{CN})_{3}(\mathrm{tp})\right]^{-}$complex ${ }^{[6]}$ in acetone/nitromethane solution (see SI for full details). Single crystals of complex $\mathbf{1}$ could be obtained upon slow evaporation from the mother liquor. It should be noted that although the

a)

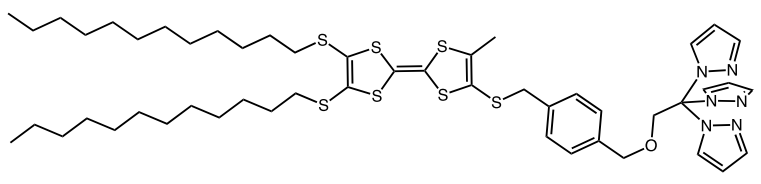

b)

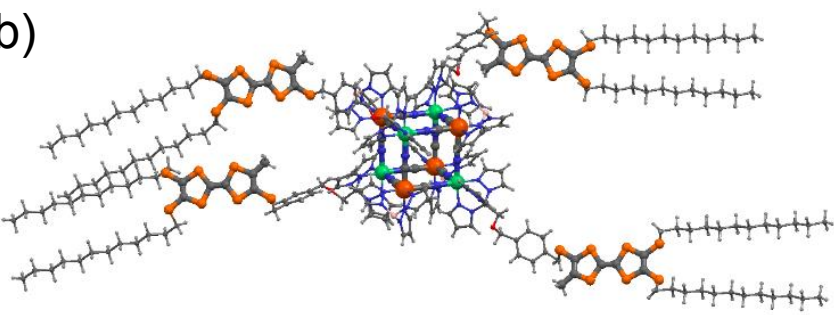

Figure 1. a) Chemical structure of L; b) Proposed structure of compound 1 based on collected structural data and complimentary analyses. Counter anions and solvent molecules are not shown. Colour code; Fe: dark orange, $\mathrm{Ni}$ : green, S: light orange, N: blue, C: dark grey, B: pink, H: light grey. 
collected X-ray diffraction data for the single crystals was not of sufficient resolution to finalize the analyses, the positions of both the central metal and cyanide ions, along with tridentate capping ligands of the core were unambiguously located (the partial crystal structure obtained at $100 \mathrm{~K}$ is shown in Figure S1). An anomalously high $R 1$ value of 0.3224 was due to the large unit cell volume and high disorder of the ligand moieties, solvent molecules and counter-anions. We note that attempts to improve resolution of the crystal structure using a synchrotron source did not provide significantly better data than the conventional XRD analysis, which is unsurprising given the general difficulties encountered in both obtaining high quality single crystals of compounds containing long-chain alkanes and resolving the significant disorder arising from such. Our analysis does confirm however, that 1 consists of a core of four iron and four nickel ions bridged by twelve cyanide ions to form a cubic moiety of formula $\left[\mathrm{Fe}^{\prime \prime \prime}{ }_{4} \mathrm{Ni}_{4}{ }_{4}(\mathrm{CN})_{12}\right]^{8+}$. The cyanometalate core is further supported by a combination of four (tp) ${ }^{-}$and four $\mathbf{L}$ capping ligands to yield the intact compound, $\mathbf{1}$. We note that the IR spectrum of 1 exhibits a clear peak at $2170 \mathrm{~cm}^{-1}$, which we and others have previously found to be characteristic of $\mathrm{M}^{\text {III-}}-\mathrm{CN}-\mathrm{M}^{\prime \prime}$ bridges, ${ }^{[7]}$ and detailed characterization of the electronic structure of $\mathbf{1}$ is provided in the following.

Electrospray ionization mass spectrometry (ESI-MS) was employed to both help support the structural characterization of 1 and approximate its solution stability. Positive mode analysis in the range of $1000-2000 \mathrm{~m} / \mathrm{z}$ showed a series of complex groupings of peak envelopes which could be attributed to 4+ and $3+$ ions corresponding to both the intact compound and fragmented species in which the ligand groups had been cleaved during the ionization process (see SI for mass spectrum and comprehensive peak assignments). In particular, peaks observed at $\mathrm{m} / \mathrm{z}=1403.0$ and 1899.7 could be assigned to $\left.\left\{\left(\mathrm{Fe}^{\mathrm{III}}{ }_{4} \mathrm{Ni}_{4}{ }_{4}(\mathrm{CN})_{12}\right)(\mathrm{tp})_{4}(\mathrm{~L})_{4}\right\}\right\}^{4+} \quad$ and $\quad\left\{\left[\mathrm{Fe}^{\mathrm{II \prime}}{ }_{4} \mathrm{Ni}_{4}{ }_{4}(\mathrm{CN})_{12}\right)(\mathrm{tp})_{4}(\mathrm{~L})_{4}\right]$ $\left.\left(\mathrm{BF}_{4}\right)\right\}^{3+}$, respectively, supporting our initial structural analysis.

Dc magnetic susceptibility data of $\mathbf{1}$ were collected in the temperature range of $1.8-300 \mathrm{~K}$ (Figure S3), and the $\chi_{\mathrm{m}} T$ vs. $T$ plots are shown in Figure S3. The $\chi_{\mathrm{m}} T$ value of 1 at $300 \mathrm{~K}$ was $7.99 \mathrm{emu} \mathrm{mol}^{-1} \mathrm{~K}$, which corresponds to the expected value (8.02 emu mol-1 K) for four uncorrelated spins on the $\mathrm{Nill}$ ions ( $S$ $=1, g=2.3)^{[8]}$ and four low-spin (LS) Fe ${ }^{\text {III }}$ ions $(S=1 / 2, g=$ 2.7). ${ }^{[9]}$ The $\chi_{\mathrm{m}} T$ values gradually increased as the temperature was lowered, reaching a maximum value of $19.94 \mathrm{emu} \mathrm{mol}^{-1} \mathrm{~K}$ at $5 \mathrm{~K}$, before an abrupt decrease to $18.56 \mathrm{emu} \mathrm{mol}^{-1} \mathrm{~K}$ at $1.8 \mathrm{~K}$. This indicates the occurrence of ferromagnetic interactions between the LS Fe ${ }^{\text {III }}$ and Nill ions. The magnetic data of $\mathbf{1}$ was analyzed by MAGPACK ${ }^{[10]}$ and full details are described in the SI. Magnetization experiments (Figure S4) conducted at $1.8 \mathrm{~K}$ showed unsaturated values of $10.7 N \beta$, which is similar to the values reported for the previously reported discrete $\left[\mathrm{Fe}^{\mathrm{III}}{ }_{4} \mathrm{Ni}_{4}\right]$ cube, suggesting an $S=6$ spin ground state. ${ }^{[11]}$ Note that no frequency dependent response was observed in ac susceptibility measurements.

Cyclic voltammetry (CV) measurements were conducted on both $L$ and $\mathbf{1}$ in acetonitrile and dichloromethane, respectively, and the cyclic voltammograms are depicted in Figures S5 and 2, shown above (observed redox potentials are summarized in

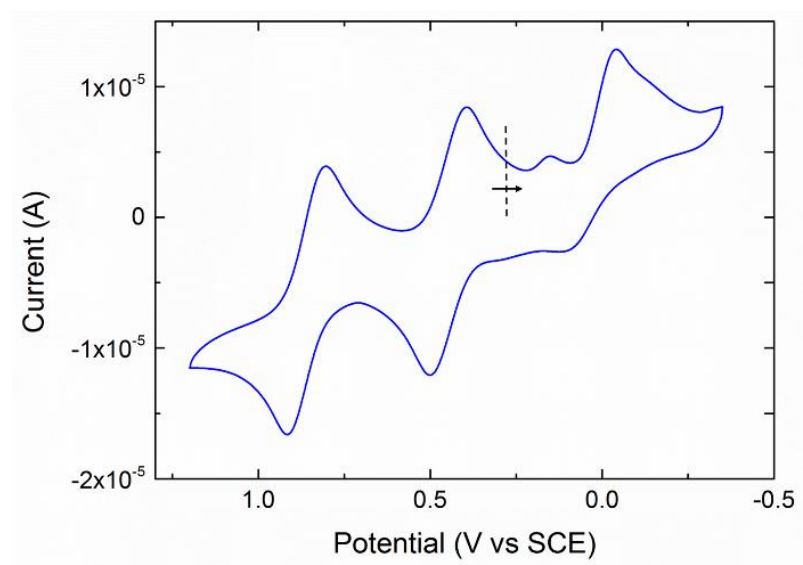

Figure 2. Cyclic voltammogram of a $0.5 \mathrm{mM}$ acetonitrile solution of compound 1 at a scan rate of $100 \mathrm{mV} \mathrm{s}^{-1}$. The pseudo-reversible redox couples located in the positive region of the spectrum correspond to TTF oxidation, showing the donor character of 1 , whereas the irreversible waves below $0.25 \mathrm{~V}$ correspond to the acceptor character of 1 via Fe $\mathrm{F}^{\text {III }}$ reduction. The dashed line and arrow indicate the open circuit potential and scan direction.

Table S2). The redox behaviour of $\mathbf{L}$ can be attributed solely to the TTF moieties, with two reversible one-electron oxidation waves observed at $E^{0}=0.46$ and $0.78 \mathrm{~V}$ (vs. SCE). The peakto-peak separations $\left(\Delta E_{\mathrm{p}}\right)$ were 0.08 and $0.07 \mathrm{~V}$, indicative of quasi-reversible redox processes. Corresponding measurements on 1 showed equivalent two-step oxidation corresponding to the TTF units at $E^{0}=0.45$ and $0.86 \mathrm{~V}$, in addition to largely irreversible reduction waves below $0.20 \mathrm{~V}$ which can be ascribed to $\mathrm{Fe}^{\|l\| \rightarrow \|}$ reduction processes. Note that this is in good agreement with previous studies of similar compounds. ${ }^{[4]}$

The gelation properties of $\mathbf{1}$ were examined in 1,2dichlorobenzene by using the "test-tube inversion" method. ${ }^{[12]}$ Upon dissolving 1 in 1,2-dichlorobenzene, a red gel was formed over the course of 1 week (concentration $=4 \mathrm{wt}$. \%) at room temperature. The crystalline sample of 1 , and its 4 wt. \% solution and gel are shown in Figure 3 (a), (b) and (c). The same gelation behaviour was observed for $4,6,8,10$ and 12 wt. \% solutions where all gels were semi-transparent and stable at ambient conditions. The gel-sol transformation can be considered as a dissolution process where, for an ideal solution, the molar concentration $c$ can be expressed as $\ln c=-\Delta H_{\text {melt }} /$ $R T+$ constant, where $\Delta H_{\text {melt }}$ is the enthalpy of fusion. ${ }^{[13]}$ The gel melting points of the $4,6,8,10$ and 12 wt. \% mixtures were thus measured using a water bath and the results are summarized in Table S3. With the natural logarithm of concentration $(\ln c)$ in proportion to the inverse of temperature $\left(T^{-1}\right)$, the critical gelation concentration (CGC) and $\Delta H_{\text {melt }}$ were estimated to be $2.5 \mathrm{wt} \% \%$ and $38 \mathrm{~kJ} \mathrm{~mol}^{-1}$ respectively, at $300 \mathrm{~K}$ (Figure S6). The value of $\Delta H_{\text {melt }}$ was thus in good agreement with the enthalpy of fusion expected of organogels, $\left.{ }^{[14}, 3 c\right]$ indicating the existence of weak intermolecular interactions as the primary gelation force. Additionally, differential scanning calorimetry (DSC) data for the 12 wt. \% gel of 1 in 1,2dichlorobenzene was recorded. Heat flow vs. time and 
a)

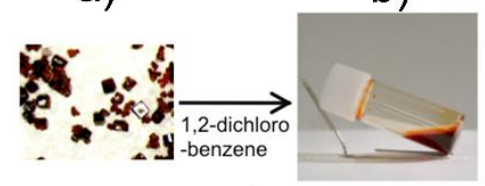

d)

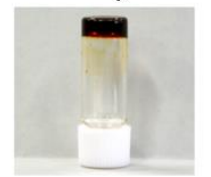

f)
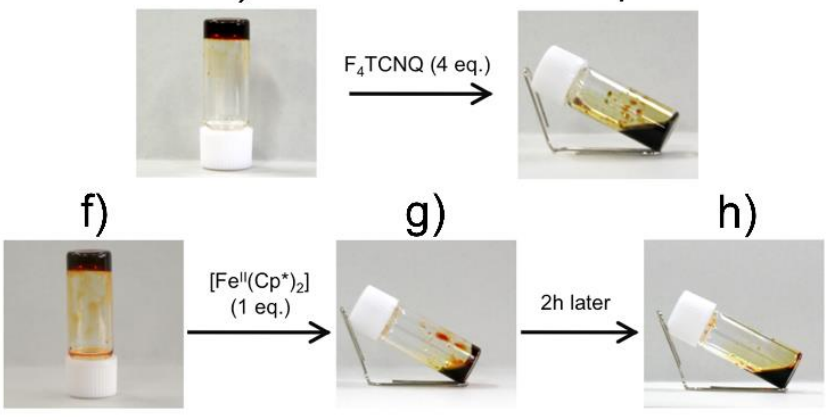

h) c)

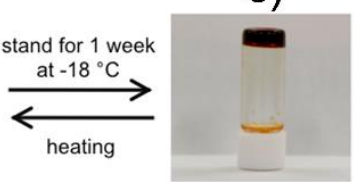

e)
Figure 3. Sol-gel transformations of 1 in 1,2-dichlorobenzene solution. (a) Red block crystals of 1 . (b) 4 wt. \% red solution at r.t. (c) 4 wt. \% red gel. The gel was formed at $-18^{\circ} \mathrm{C}$ over 1 week and was then returned to room temperature; the photograph was taken at room temperature. (d) and (f) 4 wt $\%$ red gel of 1 . (e) 4 wt. \% green solution of 1 at room temperature containing 4 equivalent amounts of $\mathrm{F}_{4} \mathrm{TCNQ}$. (g) and (h) 4 wt. \% brownish red solution of 1 at room temperature containing 1 equivalent amount of decamethylferrocene. (g) shows the partial-gel state immediately after the reaction (within 1 minute) and $(\mathrm{h}$ ) shows the solution state formed after $2 \mathrm{~h}$.

temperature profiles in the range of -19 to $75^{\circ} \mathrm{C}$ are shown in Figure S7. Upon heating, an endothermic peak at $59^{\circ} \mathrm{C}$ was observed, corresponding to a melting phase transition from gel to solution and indicating that the thermally induced phase transition is an entropy driven process. Considering the availability of both oxidation and reduction processes, as clearly shown in the CV, we were interested to explore the effect of redox interactions on the gelation behavior of 1 . Given the wellknown formation of charge transfer (CT) complexes between TTF-containing species and TCNQ moieties, ${ }^{[14]}$ we first explored the addition of four equivalents of $\mathrm{F}_{4} \mathrm{TCNQ}$ to a $12 \mathrm{wt}$. \% solution of $\mathbf{1}$ at room temperature. Upon addition, a rapid color change was observed (from red to green), suggesting the possible formation of a CT complex between the TTF moieties and $\mathrm{F}_{4} \mathrm{TCNQ}$. Significantly, no gel transformation was observed when the green solution was cooled to $255 \mathrm{~K}$, suggesting that the formation of CT adducts disturbs the gelation process previously observed for $\mathbf{1}$ in 1,2-dichlorobenzene solution. UV-Vis-NIR titration experiments could be employed to confirm the formation of CT complexes between 1 and $F_{4} T C N Q$. Absorption spectra of 1 were recorded for $0.10 \mathrm{mM} \mathrm{1,2-}$ dichlorobenzene solutions upon addition of subsequent equivalents of $\mathrm{F}_{4} \mathrm{TCNQ}$ (Figure 4). In the native spectrum, a characteristic absorption band was observed at ca. $440 \mathrm{~nm}(\varepsilon=$ $1.69 \times 10^{4} \mathrm{M}^{-1} \mathrm{~cm}^{-1}$ ) and assigned to the ligand-to-metal charge transfer $(\mathrm{LMCT})$ band of the $\left[\mathrm{Fe}^{\prime \prime \prime}(\mathrm{CN})_{3}(\mathrm{tp})\right]^{-}$chromophore. Following addition of four equivalents of $\mathrm{F}_{4} \mathrm{TCNQ}$, new bands with peak maxima were observed at 396, 770 and $876 \mathrm{~nm}$ and were assigned to the presence of $\mathrm{TTF}^{+\cdot}, \mathrm{TTF}^{+\cdot}$ dimers and a)

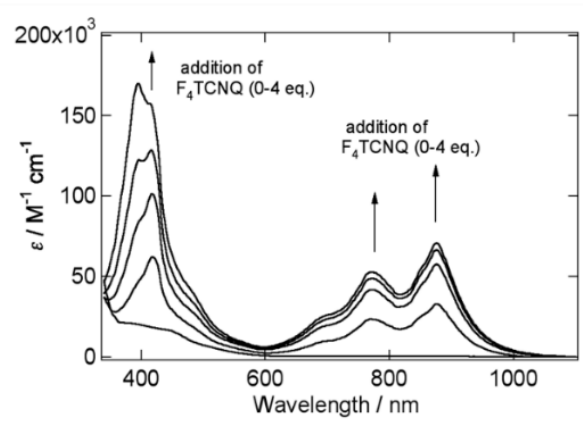

b)

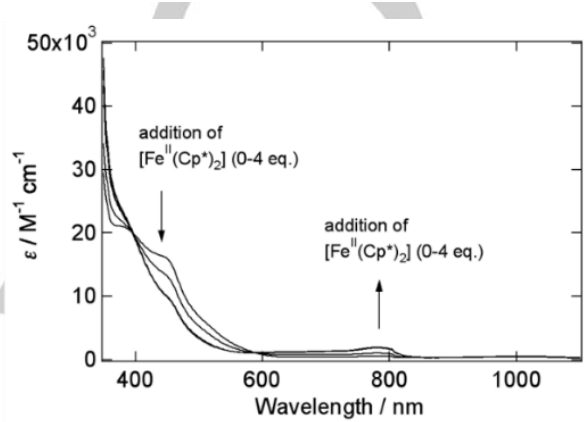

Figure 4. UV-Vis spectra of the charge transfer complexes formed by 1 upon addition of 1 to 4 equivalents of $\mathrm{F}_{4} \mathrm{TCNQ}$ (a) or [ $\left.\mathrm{Fe}\left(\mathrm{Cp}^{*}\right)_{2}\right]$ (b). In the case of [Fe( $\left(\mathrm{Cp}^{*}\right)_{2}$ ], plots of $\varepsilon$ vs. equivalents of reductant added are given in the accompanying SI for the maxima observed at both 440 and $780 \mathrm{~nm}$.

$\mathrm{F}_{4} \mathrm{TCNQ}^{-}$dimers, respectively. ${ }^{[13]}$ Most importantly, the peak centered at $414 \mathrm{~nm}$ could be assigned to the CT band between $\mathrm{TTF}^{+}$and $\mathrm{F}_{4} \mathrm{TCNQ}^{-}$, strongly indicating that charge transfer complexes between the TTF moieties of 1 and $F_{4}$ TCNQ were formed in solution. It should also be noted that the titration experiments clearly show that each TTF moiety in $\mathbf{1}$ is capable of forming a 1:1 CT complex with $\mathrm{F}_{4} \mathrm{TCNQ}$ (i.e. up to a maximum of four equivalents) (Figure S8, Scheme 1).

Further to this, the direct reaction of the stable room temperature gel with solid $\mathrm{F}_{4} \mathrm{TCNQ}$ was expected to lead to an isothermal gel to sol transformation. Four equivalents of $\mathrm{F}_{4} \mathrm{TCNQ}$ were directly added to the top surface of a $4 \mathrm{wt}$. \% gel at room temperature and the gel was quickly destroyed (without mixing and within a maximum of 20 minutes) to yield a green solution (Figure $3 d$ and e), as above. It is worth noting that the formation of CT complexes between TTF-containing gelators and TCNQ does not prevent gelation in other LMWGs, ${ }^{[15]}$ suggesting that the unique structure of $\mathbf{1}$ imposed by its cubic cyanometalate core may play an important role in its gelation properties.

In addition to oxidation waves, the CV of $\mathbf{1}$ also shows reduction waves below $0.10 \mathrm{~V}$ corresponding to the reduction of Fe"II. Decamethylferrocene was selected as an appropriate reducing agent and when a single equivalent of $\left[\mathrm{Fe}\left(\mathrm{Cp}^{*}\right)_{2}\right]$ was directly added to the top surface of a $4 \mathrm{wt} \%$ gel of $\mathbf{1}$, the gel phase collapsed almost immediately, reaching complete dissolution within $2 \mathrm{~h}$ (Figures $3 \mathrm{f}, \mathrm{g}$ and $\mathrm{h}$ )). A red to brown color change was also observed, corresponding to the partial reduction of the cyanometalate core on the $\mathrm{Fe}^{\mathrm{III}}$ centers. As before, UV-Vis-NIR absorption spectra of $\mathbf{1}$ upon titration with $\left[\mathrm{Fe}\left(\mathrm{Cp}^{*}\right)_{2}\right]$ were measured for $1 \mathrm{mM}$ 1,2-dichlorobenzene 


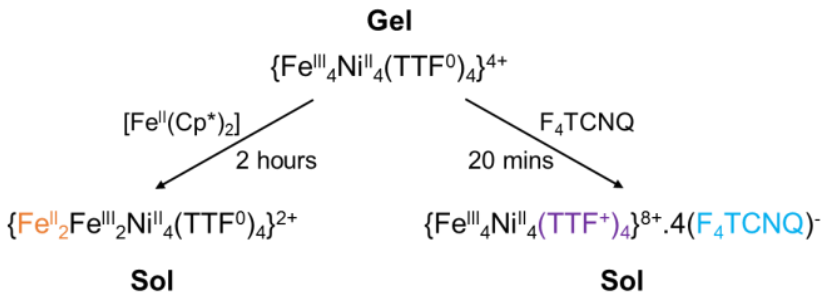

Scheme 1. Redox interactions of 1 with either $\left[\mathrm{Fe}^{\prime \prime}\left(\mathrm{Cp}^{*}\right)_{2}\right]$ or $\mathrm{F}_{4} \mathrm{TCNQ}$, showing the maximum possible reduction or oxidation, respectively, as determined by UV-vis titrations. Note that the scheme shows simplified formulae, highlighting only the metal ions and redox-active components of compound 1 . $\left\{\mathrm{Fe}^{\prime \prime \prime}{ }_{4} \mathrm{Nil}_{4}\left(\mathrm{TTF}^{0}\right)_{4}\right\}^{4+}$ corresponds to the native state of compound $\mathbf{1}$ $\left[\mathrm{Fe}^{\prime \prime \prime}{ }_{4} \mathrm{Ni}_{4}{ }_{4}(\mathrm{CN})_{12}(\mathrm{tp})_{4}(\mathbf{L})_{4}\right]\left(\mathrm{BF}_{4}\right)_{4}$. Charge balancing $\mathrm{BF}_{4}-$ anions have been omitted for clarity.

solutions (Figure 3b). As additional equivalents of $\left[\mathrm{Fe}\left(\mathrm{Cp}^{*}\right)_{2}\right]$ were introduced, the LMCT band of the $\left[\mathrm{Fe}^{\prime \prime \prime}(\mathrm{CN})_{3}(\mathrm{tp})\right]^{-}$ chromophore (centered around $440 \mathrm{~nm}$ ) decreased in line with a simultaneous increase in absorption at higher energies (ca. 365 $\mathrm{nm}$ ), corresponding to the metal-to-ligand charge transfer $(\mathrm{MLCT})$ band associated with $\left[\mathrm{Fe}^{\prime \prime}(\mathrm{CN})_{3}(\mathrm{tp})\right]^{2-}$. A new band corresponding to the LMCT of the $\left[\mathrm{Fe}^{\mathrm{III}}\left(\mathrm{Cp}^{*}\right)_{2}\right]^{+}$cation also appeared at around $780 \mathrm{~nm}$, corroborating electron transfer between 1 and $\left[\mathrm{Fe}^{\| \prime}\left(\mathrm{Cp}^{\star}\right)_{2}\right]$. As shown in Figure S9, the spectral change effectively saturated after just two equivalents of $\left[\mathrm{Fe}^{\prime \prime}\left(\mathrm{Cp}^{*}\right)_{2}\right]$ were added, indicating that a $\left\{\mathrm{Fe}^{\mathrm{III}}{ }_{2} \mathrm{Fe}_{2}{ }_{2} \mathrm{Ni}_{4}{ }_{4}\left(\mathrm{TTF}^{0}\right)_{4}\right\}^{2+}$ species was obtained from the initial $\left\{\mathrm{Fe}^{\mathrm{III}}{ }_{4} \mathrm{Ni}_{4}{ }_{4}\left(\mathrm{TTF}^{0}\right)_{4}\right\}^{4+}$ state. In this case, the multi-redox behaviour of the cyanometalate core can also be employed in order to effect a gel-sol transition although the mechanism by which this occurs is less clear. An indirect process involving the loss of two $\mathrm{BF}_{4}^{-}$anions per cluster unit would however, at least help to explain the significantly longer timescale of the gel-sol transformation observed in this case.

The electronic state of $\mathbf{1}$ and the formation of both the charge-transfer and mixed-valence states of the complex could also be confirmed by IR measurement, with the results shown in Figure S10. The IR spectrum of the a 4 wt. \% xero-gel of 1 (see SI for additional characterization of the xero-gel state) exhibited a peak at $2170 \mathrm{~cm}^{-1}$, corresponding to $\nu_{\mathrm{CN}}$ stretching modes characteristic of $\mathrm{M}^{\mathrm{III}}-\mathrm{CN}-\mathrm{M}^{\mathrm{II}}$ bridges. ${ }^{[7]}$ Likewise, the IR spectrum of a powder sample, prepared by addition of four equivalents of $\mathrm{F}_{4} \mathrm{TCNQ}$ followed by evaporation of the mixture at room temperature, showed peaks at both 2171 and $2193 \mathrm{~cm}^{-1}$, indicating the presence of both $\mathrm{Fe}^{\mathrm{III}}-\mathrm{CN}-\mathrm{Ni}$ II bridges and $\mathrm{F}_{4}$ TCNQ anion radicals. The powder prepared from evaporation of a mixture of one equivalent of $\left[\mathrm{Fe}\left(\mathrm{Cp}^{*}\right)_{2}\right]$ and the $4 \mathrm{wt}$. \% gel, however, exhibits peaks at both 2171 and $2080 \mathrm{~cm}^{-1}$, characteristic of the presence of both $\mathrm{Fe}^{\mathrm{III}}-\mathrm{CN}-\mathrm{Ni}^{\prime l}$ and $\mathrm{Fe}^{\mathrm{II}}-\mathrm{CN}$ $\mathrm{Nill}$ bridges, respectively.

In conclusion, a new discrete metallogelator was synthesized from the reaction of $\mathrm{Ni}(\mathrm{II})$ ions and a hydrophobic TTF ligand with a fac-tricyanoferrate complex. The magnetic properties, electrochemistry and gelation behaviour of 1 have been characterized and in 1,2-dichlorobenzene, $\mathbf{1}$ yielded a stable, thermoreversible gel-phase with a critical gelation concentration of $2.5 \mathrm{wt}$. \% at $300 \mathrm{~K}$. Significantly, 1 behaves as a multi-redox active gel, exhibiting redox-driven gel-to-sol transitions via its interaction with various redox agents. To the best of our knowledge, this is the first time such interactions have been observed to impede gel formation and produce rapid gel-to-sol transformations. Furthermore, this material is the amongst the most structurally complex discrete metallogel reported thus far and the synthesis of the new ligand, L, should greatly facilitate future studies into a range of new and more functionally advanced coordination complex based metallogelators, paving the way towards new advances in 'smart' soft-material design.

\section{Acknowledgements}

This work was supported by JSPS KAKENHI Grant Number JP16H06523 (Coordination Asymmetry), JPS25248014, BBD28038, JP26288021, and JP26410065.

J.M.C. and R.-J.W. would like to thank JSPS for their financial support.

Keywords: Stimuli-responsive Materials $\cdot$ Sol-gel $•$ Redox

Active $\cdot$ Cyanometalate $\cdot$ Supramolecular Chemistry

[1] a) P. Terech, R.G. Weiss, Chem. Rev.1997, 97, 1515-1566. L. A Estroff, A. D. Hamilton, Chem. Rev. 2004, 104, 1201-1217; b) A. R Hirst, B. Escuder, J. F. Miravet, D. K. Smith, Angew. Chem. Int. Ed 2008, 47, 8002-8018; c) K. Sada, M. Takeuchi, N. Fujita, M. Numata, S Shinkai, Chem. Soc. Rev. 2007, 36, 415-435.

[2] a) R. V. Ulijn, J. Mater. Chem. 2006, 16, 2217; b) T. Miyata, Polym. J. 2010, 42, 277; c) A. Dawn, T. Shiraki, S. Haraguchi, S.-i. Tamaru, S. Shinkai, Chem. Asian. J. 2011, 6, 266.

[3] a) S. Kawano, N. Fujita, S. Shinkai, J. Am. Chem. Soc. 2004, 126 8592-8593; b) H. Matsukizono, K. Kuroiwa, N. Kimizuka, J. Am. Chem. Soc. 2008, 130, 5622-5623; c) O. Roubeau, A. Colin, V. Schmitt, R Clérac, Angew. Chem. Int. Ed. 2004, 43, 3283-3286; d) N. Komiya, T. Muraoka, M. lida, M. Miyanaga, K. Takahashi, T. Naota, J. Am. Chem. Soc. 2011, 133, 16054-16061; e) A. Kishimura, T. Yamashita, T. Aida, J. Am. Chem. Soc. 2005, 127, 179-183; f) T. Fujigaya, D. L. Jiang, T. Aida, Chem. Asian J. 2007, 2, 106.

[4] K. Mitsumoto, H. Nishikawa, G. N. Newton, H. Oshio, Dalton Trans., 2012, 41, 13601-13608.

[5] a) K. Kuroiwa, N. Kimizuka, Chem. Lett, 2010, 39, 790-791: b) T. Kitahara, M. Shirakawa, S. Kawano, U. Beginn, N. Fujita, S. Shinkai, J. Am .Chem. Soc. 2005, 127, 14980-14981; c) C. Wang, D. Zhang, D. Zhu, J. Am. Chem. Soc. 2005, 127, 16372-16373; d) R. Afrasiabi, H.-B. Kraatz, Chem. Eur. J. 2015, 21, 7695.

[6] E. S. Koumousi, I.-R. Jeon, Q. Gao, P. Dechambenoit, D. N. Woodruff, P. Merzeau, L. Buisson, X. Jia, D. Li, F. Volatron, C. Mathonière, R Clérac, J. Am. Chem. Soc. 2014, 136, 15461.

[7] a) M. Nihei, M.Ui, N. Hoshino and H. Oshio, Inorg. Chem. 2008, 47, 6106-6108; b) M. Shatruk, A. Dragulescu-Andrasi, K. E. Chambers, S.A. Stoian, E. L. Bominaar, C. Achim and K. R. Dunbar, J. Am. Chem. Soc. 2007, 129, 6104-6116.

[8] D. Li, R. Clérac, G. Wang, G. T. Yee and S. M. Holmes, Eur. J. Inorg Chem. 2007, 1341-1346.

[9] D. Li, R. Clérac, O. Roubeau, E. Harté, C. Mathonière, R. L. Bris, S. M. Holmes, J. Am. Chem. Soc. 2008, 130, 252-258 
[10] J. J. Borras-Almenar, J. M. Clemente-Juan, E. Coronado, B. S. Tsukerblat, J. Comput. Chem. 2001, 22, 985-991.

[11] a) D. Li, S. Parkin. G. Wang, G. T. Yee, R. Clérac, W. Wernsdorfer and S. M. Holmes, J. Am. Chem. Soc. 2006, 128, 4214-4215; b) D. Li, S Parkin, R. Clérac, S. M. Holmes, Inorg. Chem. 2006, 45, 7569-7571.

[12] M. Shirakawa, N. Fujita, T. Tani, K. Kaneko, M. Ojima, A. Fujii, M. Ozaki, S. Shinkai, Chem. Eur. J. 2007, 13, 4155-4162.

[13] F. Placin, J. -P. Desvergne, J. -C. Lassègues, Chem. Mater. 2001, 13, 117-121.
[14] a) A. Jain, K. V. Rao, U. Mogera, A. A. Sagade, S. J. George, Chem Eur. J. 2011, 44, 12355-12361; b) T. Endo, T. Akutagawa, T. Kajiwara, K. Kakiuchi, Y. Tatewaki, S. Noro, T. Nakamura, Bull. Chem. Soc. Jpn. 2009, 82, 968-974; c) T. Akutagawa, G. Saito, M. Kusunoki, K. Sakaguchi, Bull. Chem. Soc. Jpn. 1996, 69, 2487-2511.

[15] a) Y. Liu, N. Zheng, T. Chen, L. Jin, B. Yin, Org. Biomol. Chem. 2014 12, 6927; b) S. K. M. Nalluri, N. Shivarova, A. L. Kanibolotsky, M. Zelzer, S. Gupta, P. W. J. M. Frederix, P. J. Skabara, H. Gleskova, R. V. Ulijn, Langmuir 2014, 30, 12429. 


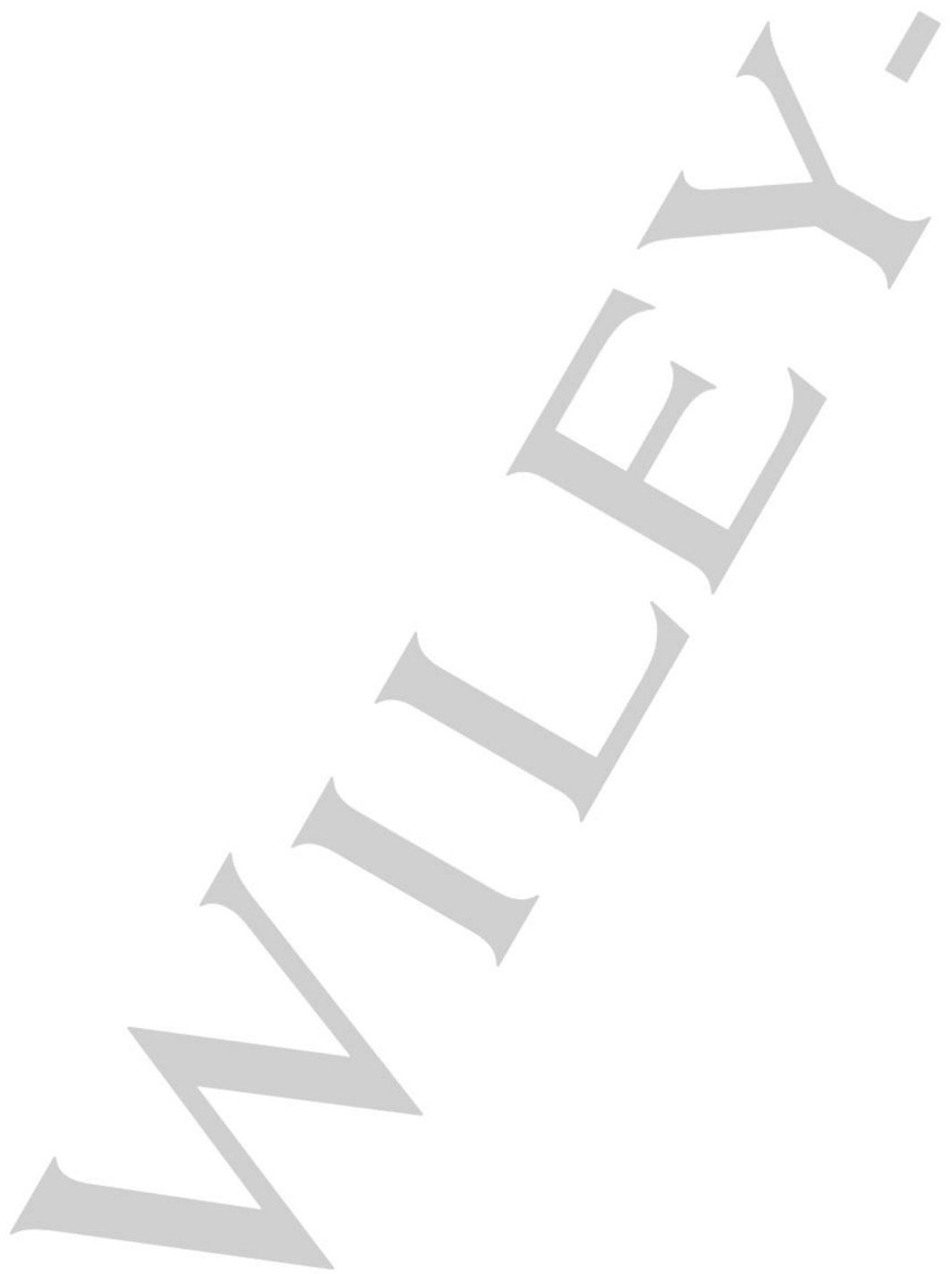

